\title{
Syphilis associated with abdominal trauma and splenic rupture in pregnancy
}

\author{
Liliana SteriU ${ }^{1,2)}$, Roxana-Cleopatra Penciu ${ }^{1,2)}$, Corina MădăLina Nour ${ }^{1)}$, Silvia IzVORANU 1,2), \\ IULIA-DiANA MOCANU ${ }^{1,2)}$, GABRIELA-IZABELA BĂLTĂTESCU ${ }^{3)}$, OANA COJOCARU ${ }^{2,4)}$, VLAD-IUSTIN TICA ${ }^{1,2)}$ \\ ${ }^{1)}$ Department of Obstetrics and Gynecology, Sf. Apostol Andrei Emergency County Hospital, Constanţa, \\ Romania \\ 2) Faculty of Medicine, Ovidius University of Constanţa, Romania \\ ${ }^{3)}$ Research Center - CEDMOG, Faculty of Medicine, Ovidius University of Constanta, Romania \\ 4) Department of Clinical Pathology, Sf. Apostol Andrei Emergency County Hospital, Constanta, Romania
}

\begin{abstract}
We present a case of a pregnant woman in the third trimester who came to the Department of Emergency, Sf. Apostol Andrei Emergency County Hospital, Constanţa, Romania, in September 2016, for abdominal pain and ascites. After admission, the patient was periodically tested (biochemically and by ultrasound). We also payed attention to the fetal well-being. During the hospitalization, the patient was also found positive for syphilis. Biochemical values have progressively altered, the fetus started to present acute fetal distress and the patient gave birth by Caesarean section after two days of hospitalization. The intraoperatory surprise was hemoperitoneum caused by posttraumatic splenic rupture. The relevance of this case consists in its rarity (we were not able to find in the literature a case with the association of pregnancy, syphilis, trauma, and splenic rupture), in the difficult histopathological clear assertion and in the clinical awareness of such a condition.
\end{abstract}

Keywords: syphilis, trauma, splenectomy, pregnancy, endometriosis.

\section{Introduction}

Syphilis is an infectious disease caused by Treponema pallidum, which is transmitted by sexual contact or vertically, from the mother to the fetus, after 20 gestational weeks. Pregnancy does not affect the clinical expression of syphilis. Syphilis can be transmitted to the fetus: transplacental (the most common way) or during labor, through direct contact with genital lesions [1]. Offspring infection can induce malformations, which must be causally differentiated from other, non-infectious, fetal/adnexal abnormalities $[2,3]$.

Syphilis had an increased incidence until 1940, when the introduction of Penicillin decreased the clinical effects, but without eradicating them.

The incidence of syphilis in Romania has decreased in the past 10 years, but still remains one of the highest in Europe. In 2016, the incidence of syphilis was 4.83/100 000 . The incidence is increased for the age groups 20-34 years old. In 2016, there were 424 women with syphilis - 109 (25.7\%) of them were pregnant - and four congenital syphilis cases were registered. Among pregnant women diagnosed with syphilis, $21(19.3 \%)$ cases were detected in the first trimester of pregnancy, $29(26.6 \%)$ cases in the second trimester of pregnancy, $58(53.2 \%)$ cases in the third trimester of pregnancy and for one case $(0.9 \%)$ the age of pregnancy was not specified [4].

The data of the splenic rupture in pregnancy and the puerperium is poorly represented in the literature. A review from 1958 revealed that the rupture of the spleen is more common in multiparous women and it is more likely to occur in the last trimester of pregnancy. In some cases, the splenic rupture was associated with significant trauma or a pathological spleen [5].

The factors responsible for the spleen rupture in pregnancy are not established. It is likely that a combination of causes may be responsible. Various conditions (like hypervolemia, hypertension [6] or aneurysm of splenic artery [7] are mentioned to, possibly, predispose to vascular rupture in pregnancy.

\section{Aim}

We could not find any data concerning splenic rupture in pregnancy associated with syphilis and minor trauma. This article is, up to our knowledge, a unique case report of a women who presented an association of four major conditions which never have been reported, concomitantly, until now: pregnancy, trauma, syphilis, and splenic rupture.

\section{ㄷ Case presentation}

We present the case of a 40 -year-old patient, gravida VII, para VII, who was admitted in the Department of Emergency, Sf. Apostol Andrei Emergency County Hospital, Constanţa, Romania, in September 2016, at 35 gestational weeks (approximate data, ascertained after the examination of the neonate) for abdominal pain and painful contractions. The patient gave her informed consent for using her medical data in scientific purposes, as well as for the medical treatment, according with our institutional, internal, ethical regulations.

This is an open-access article distributed under the terms of a Creative Commons Attribution-NonCommercial-ShareAlike 4.0 International Public License, which permits unrestricted use, adaptation, distribution and reproduction in any medium, non-commercially, provided the new creations are licensed under identical terms as the original work and the original work is properly cited. 
From her history, we found that she had two miscarriages for which she was suspected of thrombophilia since this is a relative frequent cause for reproductive disorders in our region, but this assumption was refuted [8]. We did not find any other significant pathology but poor living conditions and untreated syphilis.

The patient had no visit to any doctor during the respective pregnancy. She did not have any treatment, either (including Folic Acid or Iron).

The physical examination revealed a respiratory and hemodynamically stable patient, with a blood pressure of $106 / 58 \mathrm{mmHg}$, pulse of 98 heartbeats/min, without traumatic signs. The obstetrical examination revealed a fundal height of uterus of $28 \mathrm{~cm}$ (smaller than the normal expected value), irregular uterine contractions and a longue posterior closed cervix.

During the abdominal ultrasound examination, we noted a fetal heart rate of 140 heartbeats/minute, biometry of 32 weeks of gestation, cranial presentation, normal quantity of amniotic fluid and high quantity of ascites, without any other intraabdominal pathological changes.

Laboratory tests, at admission, revealed a hemoglobin $(\mathrm{Hb})$ of $8.3 \mathrm{~g} / \mathrm{dL}$ and a hematocrit of $25.8 \%$. The number of leukocytes was $16080 / \mu \mathrm{L}$ and the level of platelets was normal $(201000 / \mu \mathrm{L})$. The coagulation parameters had normal values for pregnancy [international normalized ratio (INR) was 0.93 , activated partial thromboplastin time (aPTT) was $40.4 \mathrm{~s}$. Hb levels remained stationary on repeated testing, even after 2 units of blood were administered. The patient has remained hemodynamically and respiratory stable for two days.

Syphilis was confirmed by immunological serological tests: rapid plasma reagin (RPR)-carbon positive, Treponema pallidum hemagglutination assay (TPHA) 1:80 (++++), $1: 160(++++), 1: 320(++++)$, without any clinical signs.

Two days after admission, the patient presented abdominal pain, the vital signs deteriorated, and the $\mathrm{Hb}$ levels decreased by $2 \mathrm{~g} / \mathrm{dL}$. Fetal bradycardia was recorded on the cardiotocography. An emergency Caesarean section was performed for acute fetal distress, and a $2000 \mathrm{~g}$ female, Apgar score of 5, was delivered. The newborn was harmonic for gestational age, with a fetal length of $46 \mathrm{~cm}$ and a cranial perimeter of $30 \mathrm{~cm}$. The ponderal index was normal for preterm newborn -2.11 . The leukocytes level was increased $(21030 / \mu \mathrm{L})$ and the value of $\mathrm{Hb}$ was normal.

During surgery, approximately one liter of blood and clots were found when opening the peritoneal cavity. A surgeon was, therefore, called and found large quantities of blood and clots, predominantly in the left paracolic gutter, and splenic area. A grade III splenic laceration was found, with a subcapsular hematoma - and splenectomy was performed.

Postoperative, the patient received 2 units of blood and 2 units of plasma.

The level of platelets increased after surgery to $1242000 / \mu \mathrm{L}$.

The patient was seen by a dermatologist and diagnosed with latent syphilis.
She was also seen by a gastroenterologist, a hematologist, and a cardiologist. They all concluded that the postoperative progress was favorable.

The evolution of both the mother and the newborn was favorable. They both received Penicillin, the mother for 10 days, and the baby only for three days because the serological tests for syphilis to newborn were negative.

Postoperative, the anamnesis was resumed, and, after further questions, the patient admitted being abused by her husband prior to admission (including being hit in the abdomen).

The excised spleen and also the placenta were performed in the Department of Pathology, Sf. Apostol Andrei Emergency County Hospital, Constanţa. The specimens were fixed in $10 \%$ neutral buffered formalin and paraffin embedded. The sections were first stained with Hematoxylin-Eosin (HE) and then microscopic slides were scanned and photos were taken with HuronTISSUEScope 4000XT. Macroscopic examination revealed placenta measuring 15/14/1.5 cm, umbilical cord with paracentral insertion and normal colored membranes. The spleen with slightly increased length, up to $15 \mathrm{~cm}$, presented ruptured capsule and hematoma in splenic parenchyma. On the routine staining (HE), histopathological (HP) examination revealed focal hyalinized capsule with intracapsular acute inflammatory cells (Figure 1), splenic hematoma (Figure 2) and subcapsular abscesses (Figure 3). Splenic parenchyma was slightly disorganized, with hypoplastic white pulp, with loss of the boundaries between the white pulp regions. Follicular structures were distinct from the red pulp and periarteriolar T-cell zone. Plasma cells were present in the red pulp and apoptotic bodies and tingible bodies macrophage appears in the marginal zone.

The specific staining for spirochetes did not find any microbial element. Also, no endometrial glandular structure was found.

Microscopic examination of the placenta showed mature architecture of the villi (Figure 4). The examination also revealed villous hypovascularity, focal villous fibrosis and mild localized increased of the syncytiotrophoblastic knots. Minimal lymphoplasmocytic villitis was found.

\section{ㅁ Discussions}

Beside the rarity of this case (no literature data found on the combination of the mentioned four factors), we must pay attention to domestic violence and to performing a correct and complete anamnesis.

There are some circumstances that may suggest domestic violence: diminished self-image, more visits that necessary to physician or partner insisting on being present for discussions and examination [9, 10]. The American College of Obstetricians and Gynecologists and the American Academy of Pediatrics recommend screening for domestic violence to all pregnancy women. All signs and symptoms that may suggest that abuse should be reported by all family physicians (American Academy of Family Physicians). The same recommendations are supported by the U.S. Preventive Services Task Force $[10,11]$. 


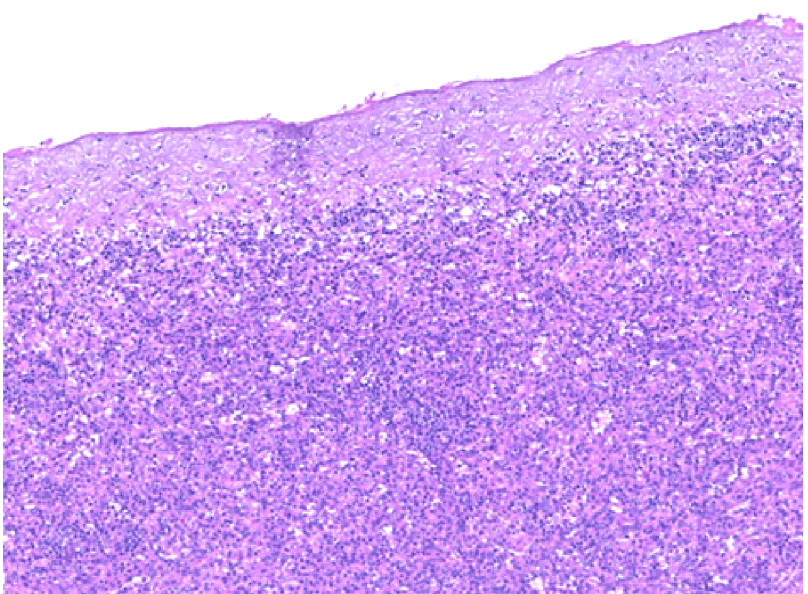

Figure 1 - Microscopic features of the spleen with hyalinized capsule and with intracapsular neutrophils (HE staining, $\times 40$ ).

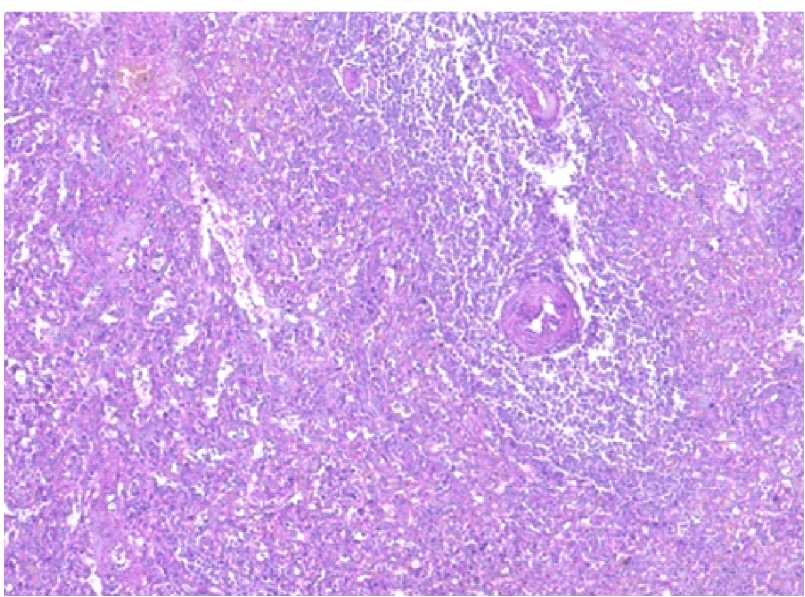

Figure 3 - Morphopathological features of the spleen with focal intra-parenchymatous abscesses, plasma cells present in the red pulp, apoptotic bodies and tingible bodies macrophage appear in the marginal zone (HE staining, $\times 100$ ).

The management of pregnant patient with an abdominal trauma is difficult and requires a multidisciplinary team [11]. Clinical examination in pregnancy is less reliable as the signs of peritoneal irritation can be less obvious. Furthermore, image diagnostic techniques may not be readily available because of the pregnancy. All those facts can delay the diagnosis. It was difficult to suspect a splenic rupture, preoperatively, in a pregnant patient who denied any trauma and who had no traumatic marks. Recent studies indicate a predisposition to rupture of the spleen that is immunological stimulated, as evidenced by alterations of lymphocytes in people with splenic trauma [12]. This was especially difficult as we could not identify elements of other (mentioned above) pain-inducing pathologies. Nor could we relate the pain to other conditions related to labor/uterine contractions [13]. The patient has not been previously infertile - so no reported hormonal or hepatic changes could be considered [14, 15]. However, after surgery and after thorough questioning, the patient admitted to being assaulted. The poor living conditions might have led to a discordance between fetus weight and gestational age.

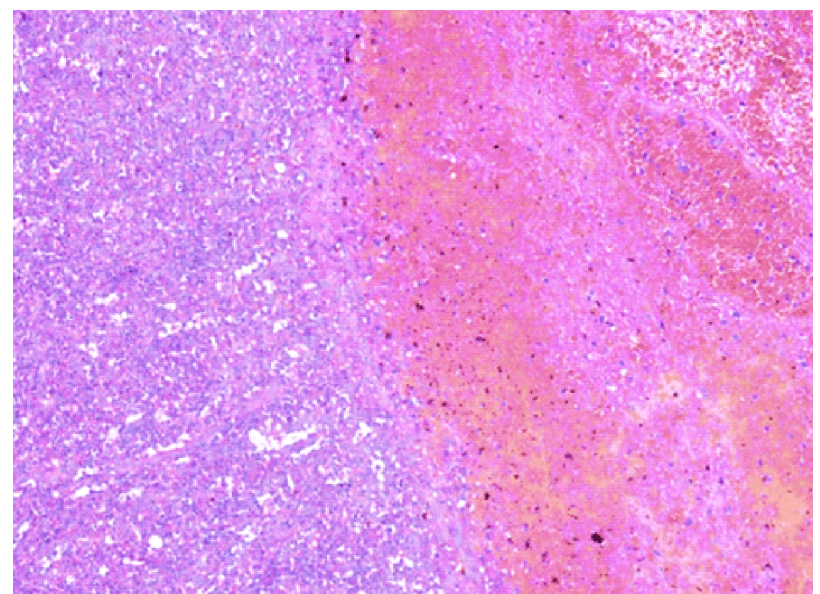

Figure 2 - Microscopic features of the spleen with a subcapsular hematoma (HE staining, $\times 100)$.

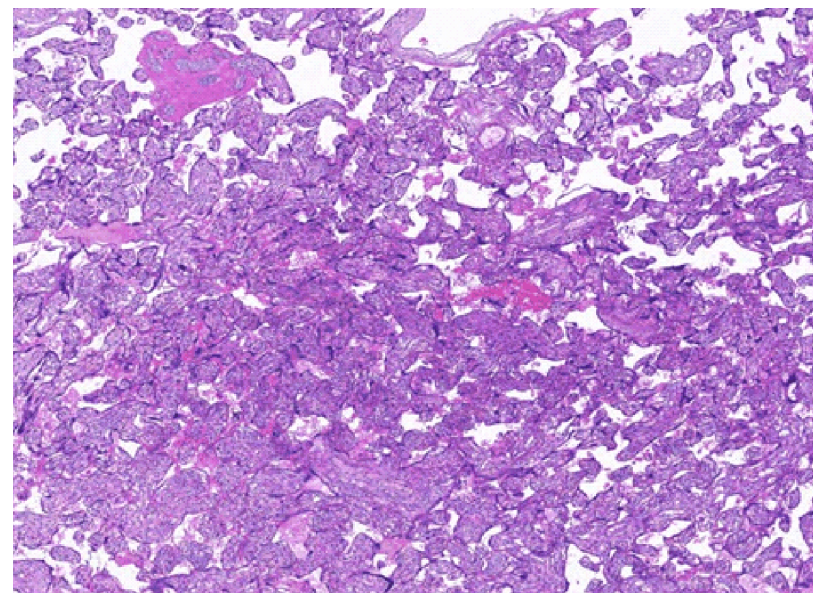

Figure 4 - Morphopathological features of the placenta with fibrotic and avascular villi and minimal lymphoplasmacytic villitis (HE staining, $\times 100)$.

View the emergency, tocolysis or variation in anesthesia [16] was not considered appropriate.

Although minor, the trauma, in the context of the vascular fragility, possibly generated by the Treponema, has led to the rupture of the spleen. The increase in the blood volume in the last pregnancy trimester, as well as the changes due to the enlarged gravid uterus, the inflammation of the spleen due to Treponema or other inflammatory disease (endometriosis, blood diseases, vascular fragility) are considered as possible risk/contributing factors for splenic rupture caused by minor trauma. The importance of cell mediated immunity in syphilis has been demonstrated in animal models [17].

In the literature, there are some studies on animals revealing that pathological lesions like intranuclear hyaline inclusions and eosinophilic inclusions are due to migration of Toxocara canis larvae. Even if unspecific inflammation may be present in different diseases, like endometriosis, blood diseases and infectious diseases and although we did not found spirochetes in the spleen, the presence of inflammation, in the described context, may suggest the existence of splenic syphilis [18]. 
Splenic rupture in pregnancy is a rare condition that, associated with hemoperitoneum, if not promptly diagnosed, can lead to both maternal and fetal death. The hemoperitoneum, in itself, in pregnancy, is associated with severe outcomes both for women and fetus. To evaluate the clinical consequences of spontaneous hemoperitoneum in pregnancy and its association with endometriosis, a systematic review was conducted and concluded that hemoperitoneum is a very serious complication of pregnancy, highly associated with adverse pregnancy outcomes and particularly relevant to women with endometriosis [19]. However, even if the splenic hematoma may have suggested endometriosis, endometrial glands were not found at microscopically examination.

Splenic abscess is an uncommon and life-threatening pathology. Due to its nonspecific clinical signs, it remains a microscopic diagnostic [20]. The splenic abscesses may suggest the presence of a parasite or spirochetes but, also, they may occur in cases of abdominal trauma. Spleen abscess may develop in immunocompromised patients as pregnant women [21]. The case that we present is one of a low immunity patient because of the association of pregnancy, syphilis, trauma, and poor social conditions. There is no precise definition of the histological parameters induced by infectious diseases. However, the spleen lesions described, in our patient - besides the inflammation markers, already mentioned previously - could have been related to the luetic infection, as hyper- or hypoplastic alterations of the white and red pulp are described also by others as a result of various parasitic organisms [22]. Although minimal, lymphoplasmocytic villitis observed in our case is another HP aspect found in the placenta related to Treponema infection, as previously reported [23].

Intrauterine growth retardation is related to a variety of clinical and pathological factors including maternal, uterine, and fetal factors. Besides the previously discussed poor living conditions of the patient, histological examination of the placenta revealed hypovascularity of the villi and increased syncytiotrophoblastic knots. This pathological aspect was reported also by other authors as involved in intrauterine fetal growth restriction [24].

\section{Conclusions}

This article is a unique case report of a woman who presented an association of four major conditions which we did not found as having been reported until now: pregnancy, trauma, syphilis, and splenic rupture. The HP findings of the spleen (hematoma, abscesses, intracapsular neutrophils, slightly disorganized parenchyma) may have suggested the presence of a parasite (like spirochetes) or endometriosis. Endometriosis was not supported by the pregnant status and by the absence of endometrial glands. Although we did not found spirochetes in the spleen, the presence of inflammation may suggest the existence of splenic syphilis and/or abdominal trauma. Even if we are in a modern age, when sexual education should be part of every family's routine, syphilis continues to be quite common among our pregnant women, even associated with domestic violence that may lead to abdominal organs rupture - and this requires careful medical awareness and work-up.

\section{Conflict of interests}

The authors declare that they have no conflict of interests.

\section{Acknowledgments}

This work is supported by the project ANTREPRENORDOC, in the framework of Human Resources Development Operational Program 2014-2020, financed from the European Social Fund under the contract number 36355/23.05.2019 HRD OP/380/6/13 SMIS code: 123847 . The research by the authors reported in this paper was supported by NIH grants AI 14262 and 19810.

This research was performed in the Center for Research and Development of the Morphological and Genetic Studies of Malignant Pathology from the Ovidius University of Constanţa, POSCCE 2.2.1. Project ID: 1844, SMIS code: 48750, CEDMOG, contract 627/11.03.2014.

\section{References}

[1] Norwitz ER, Hicks CB. Syphilis in pregnancy. UptoDate, 2018. https://www.uptodate.com/contents/syphilis-in-pregnancy? source=related_link

[2] Tica VI, Beghim M, Tica I, Zaher M, Beghim E. Anencephaly: pitfalls in pregnancy outcome and relevance of the prenatal exam. Rom J Morphol Embryol, 2009, 50(2):295-297. PMID: 19434326

[3] Tica AA, Tica OS, Georgescu CV, Mixich F, Tica VJ, Berceanu S, Ebanca E, Patrascu A, Simionescu C. Recurrent partial hydatidiform mole, with a first twin pregnancy, after treatment with clomiphene citrate. Gynecol Endocrinol, 2009, 25(8):514-519. https://doi.org/10.1080/095135909029 72125 PMID: 19499414

[4] Institutul Naţional de Sănătate Publică (INSP). Analiza evoluţiei bolilor transmisibile aflate în supraveghere. Raport pentru anul 2016. Centrul Naţional de Supraveghere şi Control al Bolilor Transmisibile (CNSCBT), Bucureşti, 2017, 72-74. https://www.cnscbt.ro/index.php/rapoarte-anuale/779-analiza -evolutiei-bolilor-transmisibile-aflate-in-supraveghere-raportpentru-anul-2016/file

[5] Sparkman RS. Rupture of the spleen in pregnancy; report of two cases and review of the literature. Am J Obstet Gynecol, 1958, 76(3):587-598. https://doi.org/10.1016/0002-9378(58) 90076-0 PMID: 13571320

[6] Hollier LM, Harstad TW, Sanchez PJ, Twickler DM, Wendel GD Jr. Fetal syphilis: clinical and laboratory characteristics. Obstet Gynecol, 2001, 97(6):947-953. https://doi.org/10.1016/s0029 -7844(01)01367-9 PMID: 11384701

[7] Holdsworth RJ, Gunn A. Ruptured splenic artery aneurysm in pregnancy. A review. Br J Obstet Gynaecol, 1992, 99(7): 595-597. https://doi.org/10.1111/j.1471-0528.1992.tb13828.x PMID: 1525102

[8] Cozaru GC, Aschie M, Mitroi A, Brinzan C, Chisoi A. The genetic profile of thrombophilia in reproductive disorders. Rev Chim (Bucharest), 2019, 70(11):3830-3834. https://doi.org/ 10.37358/RC.70.19.11.7654

[9] ***. Chapter 12: Trauma in pregnancy and intimate partner violence. In: American College of Surgeons (ACS). Advanced trauma life support (ATLS) student course manual. $10^{\text {th }}$ edition, Committee on Trauma, ACS, Chicago, USA, 2018, 227-239. https://viaaerearcp.files.wordpress.com/2018/02/atls-2018.pdf

[10] American College of Obstetricians and Gynecologists (ACOG) ACOG Committee Opinion No. 518: Intimate partner violence. Obstet Gynecol, 2012, 119(2 Pt 1):412-417. https://doi.org/ 10.1097/AOG.0b013e318249ff74 PMID: 22270317

[11] Jain V, Chari R, Maslovitz S, Farine D; Maternal Fetal Medicine Committee, Bujold E, Gagnon R, Basso M, Bos H, Brown R, Cooper S, Gouin K, McLeod NL, Menticoglou S, Mundle W, Pylypjuk C, Roggensack A, Sanderson F. Guidelines for the management of a pregnant trauma patient. J Obstet Gynaecol Can, 2015, 37(6):553-574. https://doi.org/10.1016/s1701-21 63(15)30232-2 PMID: 26334607 
[12] Turculet C, Dermengiu D, Marinescu M. Medical and forensic criteria for the assessment of abdominal trauma severity (Criterii de evaluare clinica si medico-legala a gravitatii traumatismelor abdominale). Rom J Leg Med, 2007, 15(2):141-148. https://doi.org/10.4323/rjlm.2007.141

[13] Tica AA, Tica VI, Tica OS, Dun E, Berceanu S, Tica I. Endothelin I activates the NAADP signaling complex on myometrial smooth muscle cell (Endotelina I activează complexul NAADP-dependent în miometru). Gineco.ro, 2010, 6(22):254-255

[14] Tica VI. La fertilité. Contracept Fertil Sex, 1996, 24(3):173183.

[15] Tica VI, Mares P, Teren O, Tica I, Tica AA. Preemption dimensional study for obtaining statistically significant results for the variation of gamma-glutamyl-transferase during ovarian stimulation. J Gastrointestin Liver Dis, 2007, 16(1):53-55. PMID: 17410289

[16] Tica V. A new method of anesthesia - Piritramide used intrathecally as a sole analgesic in surgery. Anesthetist, 1988, 37(10):116.

[17] Goldmeier D, Hay P. A review and update on adult syphilis, with particular reference to its treatment. Int J STD AIDS, 1993, 4(2):70-82. https://doi.org/10.1177/095646249300400 203 PMID: 8476969

[18] Maita K, Masuda H, Suzuki Y. Spontaneous lesions detected in the beagles used in toxicity studies. Jikken Dobutsu, 1977, 26(2):161-167. https://doi.org/10.1538/expanim1957.26.2 161 PMID: 560313
[19] Lier MCI, Malik RF, Ket JCF, Lambalk CB, Brosens IA, Mijatovic V. Spontaneous hemoperitoneum in pregnancy (SHiP) and endometriosis - a systematic review of the recent literature. Eur J Obstet Gynecol Reprod Biol, 2017, 219:57-65. https://doi.org/10.1016/j.ejogrb.2017.10.012 PMID: 29054042

[20] Sreekar H, Saraf V, Pangi AC, Sreeharsha H, Reddy R, Kamat $\mathrm{G}$. A retrospective study of 75 cases of splenic abscess. Indian J Surg, 2011, 73(6):398-402. https://doi.org/10.1007/ s12262-011-0370-y PMID: 23204694 PMCID: PMC3236272

[21] Ghidirim Gh, Rojnoveanu Gh, Mişin I, Gagauz I, Gurghiş R. [Splenic abscess - etiologic, clinical and diagnostic features]. Chirurgia (Bucur), 2007, 102(3):309-314. PMID:17687860

[22] Hermida MER, de Melo CVB, Lima IDS, Oliveira GGS, DosSantos WLC. Histological disorganization of spleen compartments and severe visceral leishmaniasis. Front Cell Infect Microbiol, 2018, 8:394. https://doi.org/10.3389/fcimb.2018.0 0394 PMID: 30483481 PMCID: PMC6243053

[23] Kittipornpechdee N, Hanamornroongruang S, Lekmak D, Treetipsatit J. Fetal and placental pathology in congenital syphilis: a comprehensive study in perinatal autopsy. Fetal Pediatr Pathol, 2018, 37(4):231-242. https://doi.org/10.1080/ 15513815.2018.1485798 PMID: 30207805

[24] Park SY, Kim MY, Kim YJ, Chun YK, Kim HS, Kim HS, Hong SR. Placental pathology in intrauterine growth retardation. Korean J Pathol, 2002, 36(1):30-37. https://www.jpatholtm.org/ journal/view.php?number=2142

\section{Corresponding author}

Liliana Steriu, MD, Department of Obstetrics and Gynecology, Sf. Apostol Andrei Emergency County Hospital, 145 Tomis Street, 900591 Constanţa, Romania; Phone +40721-749 549, e-mail: lilianasteriu@yahoo.com

Received: March 27, 2020

Accepted: September 24, 2020 